\title{
Is it worth it? Sketch appraisal of the relevance of proposals for new rail lines
}

\author{
P. Tzieropoulos \& R. Gindrat \\ Ecole Polytechnique Federale de Lausanne (EPFL), Switzerland
}

\begin{abstract}
Proposal for building new rail lines or extending existing ones may become a mixed blessing for transport policy managers. On the one hand, proposals may eventually lead to projects that enhance the rail network, upgrade the services and, ultimately, increase the rail patronage. On the other hand, extravagant ideas may in fine hamper legitimate developments or, at least, create enough confusion to stall the public debate about more valuable investments. It is interesting to be able to assess the relevance of an idea at the very early stages. This may help explaining to politicians and to the general public not only the advantages of a proposal but also the issues that are related to it. The tool that has been developed is based on the work done by Prof. Baumgartner, who published a quite complete catalogue of unitary costs, investment and operational as well. It uses a complete and scalable set of unitary costs that users may modify and adapt to their own context, and provides answers to questions such as:

- What is the level of public subsidy to make a project economically viable, given the expected demand and the fare structure?

- What is the required level of demand, given the public subsidy and the fare structure, to ensure the economic viability of a project?

The tool is a single, quite sophisticated, Excel file, with all the initial data customisable by the user. It is scalable: the user may opt for synthetic/global values or, on the contrary, for a more detailed cost structure with a more in-depth break-down of the unitary costs. The tool targets the early stages of a project, even when its alignment is not yet fully defined. The objective is to produce a first "Go/No Go" decision to further pursue and study an initial idea.

Keywords: sketch planning, unitary costs, Baumgartner, new rail line.
\end{abstract}




\section{Introduction: setting up the frame}

The relevance of building a new rail infrastructure should be assessed by comparing the expected costs to the expected benefits. Both notions may be limited to their strict economical sense (monetary costs vs. revenues) or be enlarged to cover social, human, and environmental costs on one hand, and social, economic, and induced benefits, on the other. Usually, overall assessment of a project (or a proposal) should encompass both views. In some countries, Great Britain or France for instance, this may even become a legal requirement, obliging to compute for any large-scale project both an economic rate of return on investment and a so called "social rate of return".

If we limit the problem to its pure economical dimension, this comes down to compute the life-cycle costs of an infrastructure, and to compare them to the cumulative revenue (from passengers, freight, and all other commercial activities). This makes it possible to evaluate the profitability of the new infrastructure or the level of public subsidy it needs to become viable. In this latter case, the legitimacy of the decision to build is based on a comparison of the public subsidies versus the expected collective gains.

For an integrated rail company, owing its resources and operating the services, there is a unique "level" of cost/benefit assessment. In a context of separation between the management of infrastructure and the operation of train services, the assessment should also be done separately: for the infrastructure manager (IM) and for the railway undertakings (RU). IMs manage their infrastructure and its maintenance and operating costs, including partially or completely the paying-off for building the infrastructure. They receive revenues from the access charges paid by the RUs. RUs set up (partly under constraint) the services. They pay the costs related to their own resources (rolling, stock, personnel, energy, etc.), and the access to the network charges. Their revenues mainly come from selling the transport services to the final customer, and depending on the case - direct public contributions for providing "public service" to the society.

\section{Objectives: what we are dealing with}

The main idea is to build a generic and customizable economic model to assess the relevance of a proposal for adding a new rail line to an existing network. The model targets the very early stage of the proposal, before a specific project is designed. It takes into account - besides the overall investment and operating costs - the expected demand level and a fare structure.

The model has two parts:

- The first one is the economic model of the IM. It helps - given some hypotheses, the unitary costs and revenues - to find the number of train paths that correspond to a break-even network operation.

- The second one is the economic model of the RU. At the current stage of the model's development, it is supposed that we deal with a single RU, 
and with passenger traffic only. The model computes the passenger volume to bring the train operation to a break-even.

Moreover, at its current stage of development, the model bears a "crosssectional" vision over time: inflation rate is zero, to by-pass the need of computing the net present value.

Using a complete and scalable set of unitary costs, that users may modify and adapt to their own context, the tool provides a documented answer to one of the following questions:

- What is the level of public subsidy to make a project economically viable, given the expected demand level and a fare structure?

- What is the required level of demand, given the public subsidy and the fare structure, to ensure the economic viability of a project?

The tool comes as a single Excel file. All the initial data is customisable by the users in case they need to replace the default values by their own ones. The tool is scalable: users may opt for synthetic/global values or, on the contrary, for a more detailed cost structure with a more in-depth break-down of the unitary costs.

As mentioned, the tool targets the early stages of a project, even when its alignment is not yet fully defined. The objective is to produce a first "Go/No Go" decision to further pursue and study an initial idea.

\section{Model structure, and default values}

\subsection{Data structure and main results}

The model uses two data categories:

- Data related to the project itself. Those data should be input by the user. They are split into infrastructure, operational, and economic data.

- Data related to the unitary costs and other general data. The model proposes default values that the users can change.

The data related to the project may be quite rough, so as to be able to test a first idea before getting down to project specifics. The project description may however be broken down to reach a fair level of detail, if the project to be assessed is developed well enough, and if detailed data are available.

Infrastructure data encompasses: the length of the sections of the new line that may be defined according to the difficulty (surface, underground, and aerial, each type being also qualified by means of a "difficulty degree"), number of tracks, targeted train speed, rail weight (in $\mathrm{kg}$ per metre of rail), and traffic load (in Giga ton kilometres per day). If relevant, users may specify the number of flying junctions, the number and type of road crossings, and the length of noise barriers. They may also input the number of stations by type, the number of marshalling yards, and the number of switches by type. Finally, users should specify the type of power (and type of current, if electricity), and - if relevant the average block length and the type of signalling.

The RU-related data includes the mix of rolling stock (fleet size by category), the availability rate for the rolling stock by category, the commercial speed of the 
services, the fare structure and prices linked to the expected share for each ticket type, the targeted directional supply (in terms of passenger seats per hour during peak), the mix of transport supply for a standard day (daily duration of peak, off-peak, and night services), and the equivalence of an annual operation in terms of number of standard working days.

Data on transport demand are peak-hour directional volumes, and the peakhour rate compared to daily volumes (this is not directly related to the variation of the transport supply over the day, as operators may opt to ensure a minimum frequency of services during off-peak periods even if the demand levels are low).

Economic and general data include the interest rates for the IM and the RU, the population density in the area, the access charges, and the energy prices.

All these data lay within a single sheet in the Excel file. This sheet displays also the main results of the model: annual revenues, expenses, and balance for both the IM and the RU. A user can therefore, within this sheet, change the project's characteristics and get immediately the effect of these changes in terms of economic performance of the project.

\subsection{The logic of the model}

The fundamental structure of the model operation is straightforward (Figure 1). One part of the model computes the IM-side of the project economics; the other part is the RU-side of the calculations, and the overall results for the two stakeholders are presented side-by-side, to help assessing the project's performance. Users can play with some basic "what if" scenarios, such as changing the demand level or the fares to achieve break-even. They may also assess the effect of a given project option on the final balance.

Basic computations reside in multiplying volumes by unitary values. Sophistication comes from the possibility given to the user to stay at a very high-level (inputting, for instance, just the line length and the difficulty rate for the infrastructure) or to get down to a fair level of detail (including the number of switches or specifying the existence of an ATC-type signalling).

\subsection{Default values: the unitary costs}

The whole set of unitary costs is based on the work of late Prof. Baumgartner [1]. The data source used to establish the figures published in this document is based on the compilation of a huge number of real-life projects. The values represent the level of prices around the year 2000, and need thus to be updated. However - at the best of these authors' knowledge - no comprehensive update has been made since then.

For each price and each cost, three different values are given: an average or median and two extreme values, the latter not taking into account exceptional cases. For each investment item in the list, Baumgartner gives figures for its investment, its economic life (to compute the depreciation over time), and its maintenance costs. Items in the document are structured as in Table 1. 


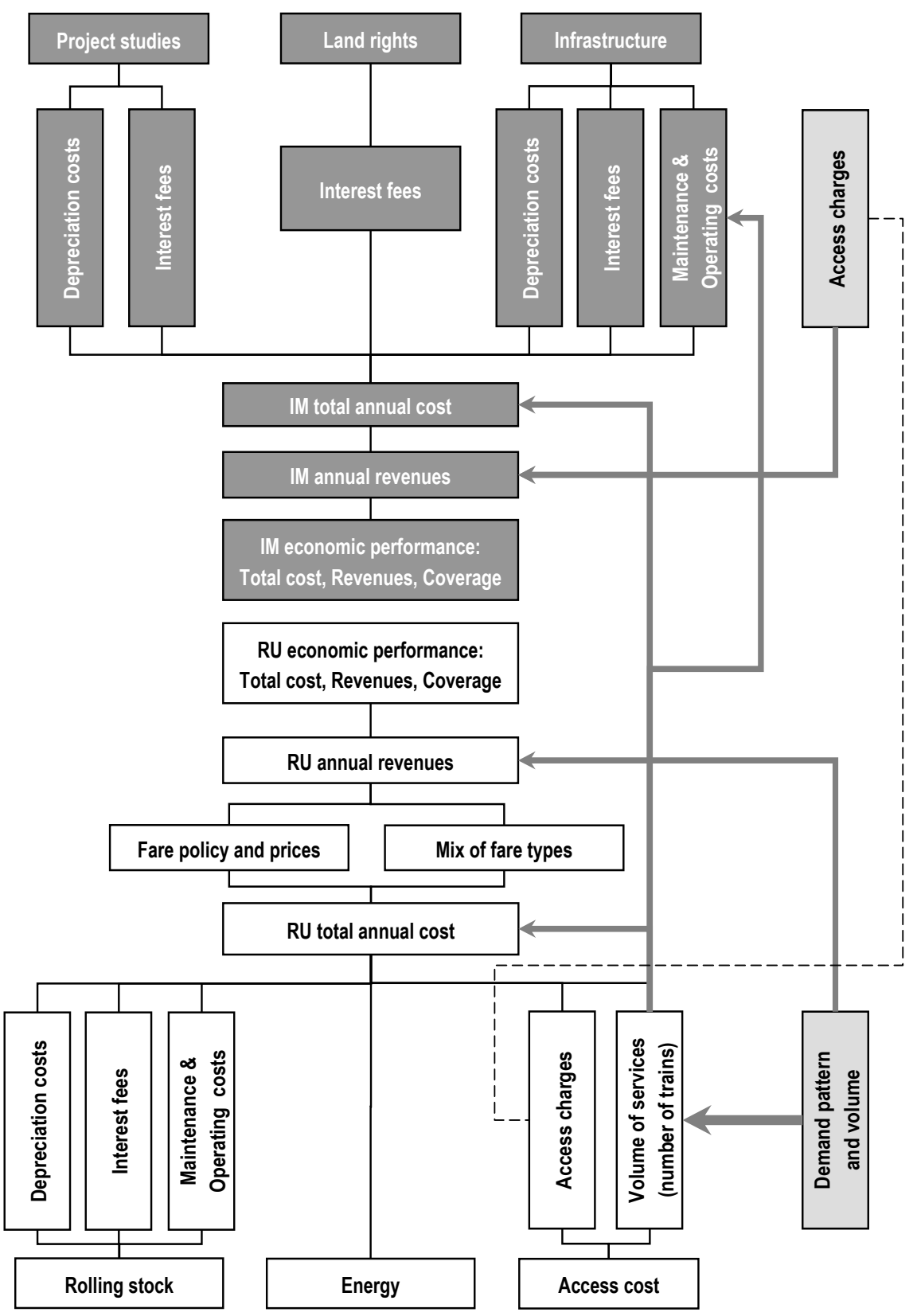

Figure 1: Basic structure of the model. 
Table 1: Unitary cost items according to [1].

\begin{tabular}{|c|}
\hline 1. Infrastructures and fixed equipment \\
\hline 1.1. Linear infrastructure and equipment \\
\hline 1.1.1. Studies \\
\hline 1.1.2. Land and rights (Investments only) \\
\hline 1.1.3. Infrastructure and track-bed \\
\hline 1.1.4. Track \\
\hline 1.1.5. Fixed equipment for electric traction \\
\hline 1.1.6. Signalling \\
\hline $\begin{array}{l}\text { 1.2. Spot fixed equipment (Points, switches, turnouts, } \\
\text { crossings/Stations/Service and light repair facilities/Maintenance and } \\
\text { heavy repair shops for rolling stock/Central shops for the } \\
\text { maintenance of fixed equipment) }\end{array}$ \\
\hline 2. Vehicles \\
\hline $\begin{array}{l}\text { 2.1. Electric traction units (Electric locomotives/Electric multiple units } \\
\text { and train sets) }\end{array}$ \\
\hline $\begin{array}{l}\text { 2.2. Diesel locomotives (North American-built diesel locomotives for use } \\
\text { on North America/North American-built diesel locomotives for } \\
\text { export/Non-North American-built diesel locomotives) }\end{array}$ \\
\hline 2.3. Coaches, passenger cars \\
\hline $\begin{array}{l}\text { 2.4. Wagons or freight cars (European wagons/North American-built } \\
\text { freight cars) }\end{array}$ \\
\hline 2.5. Equipment for combined transport \\
\hline 3. Tractive power \\
\hline 3.1. Electric traction \\
\hline 3.1.1. Average consumption (Passenger/Freight trains) \\
\hline $\begin{array}{l}\text { 3.1.2. Average unit cost of electricity at the high voltage input of } \\
\text { traction substations }\end{array}$ \\
\hline 3.2. Diesel traction \\
\hline 3.2.1. Average consumption while running (Passenger/Freight trains) \\
\hline 3.2.2. Average consumption while shunting or switching \\
\hline 3.2.3. Unit cost of gas oil or diesel oil \\
\hline
\end{tabular}

What actually the model offers is to include the complete list of Baumgartner's document, which is more detailed than presented here, and to allow the users: a) if needed, to input their own values besides the default ones; b) to activate, for each item in the list, an individual switch for using either the default values or the ones input by the users.

\subsection{Basic hypotheses}

The model uses a linear depreciation of each investment item over its life cycle. Therefore, for an economic life of e.g. 25 years, the annual depreciation is $4 \%$ of the initial investment. 
Moreover, due to its cross-sectional nature, the model computes the annual opportunity costs (or interest fees paid on a debt that is reduced gradually thanks to the amortization) as the product of the initial investment times half the interest rate. Integrating those costs over the life cycle of an item equals the total interest fees spent on the capital that has been borrowed to acquire the item (Figure 2). This logic is valid only if one assumes linear depreciation, no inflation, and constant interest rates over the entire economic life of an item. Approximation is fair enough for long life spans.

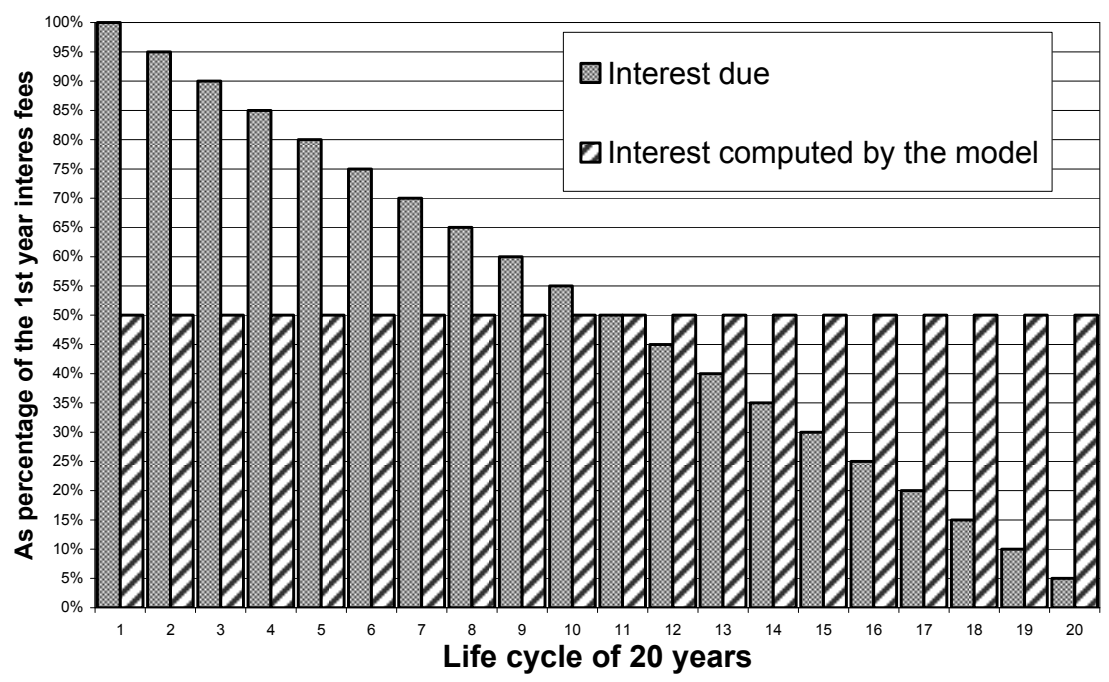

Figure 2: Computed vs. real interest fees.

As a result, capital costs for each investment item are computed as its depreciation cost, equal to the investment divided by the life span, to which is added a financial cost, equal to interest computed on half the invested amount.

The land rights do not generate any depreciation cost. The underlying hypothesis is that, through time, land gets capital gains and this added value offsets any dismantle expenses if ever the line is closed after its economic life and land is returned back to its initial use. This is an acceptable hypothesis, provided that the land is not exposed to degradation (that may be induced, for instance, by the use of weed killers). As a result, the capital cost relative to land rights is computed as the product of the whole investment for them times the interest rate.

A last hypothesis has already been mentioned: the model considers pure passenger traffic. It also limits the life span at a maximum of 50 years. 


\section{Examples of application}

To assess the usefulness of the prototype, several case studies have been modelled using the tool. Among those, three will be presented here (Table 2). The first two cases are based on lines that are in operation since several years. Figures have been adapted and updated, to create virtual projects that reflect the current conditions (as if those lines were to be built today). The aim is to compare the magnitude of the results given by the model to known and well established situations. The third case reflects a proposal for a new line, and it is used to demonstrate the usefulness of the model as an exploration tool.

Table 2: Case studies.

\begin{tabular}{|c|l|c|c|c|c|c|c|}
\hline Case & $\begin{array}{l}\text { Type of } \\
\text { service }\end{array}$ & $\begin{array}{c}\text { Number of } \\
\text { tracks }\end{array}$ & $\begin{array}{c}\text { Total } \\
\text { Length }\end{array}$ & $\begin{array}{c}\% \\
\text { undergroun } \\
\mathrm{d}\end{array}$ & $\begin{array}{c}\text { Pass/Year } \\
\text { (millions) }\end{array}$ & $\begin{array}{c}\text { Peak-Hour } \\
\text { Rate }\end{array}$ & $\begin{array}{c}\text { Peak-Hour } \\
\text { Headway }\end{array}$ \\
\hline A & Light Rail & 1 & $7,790 \mathrm{~m}$ & $7 \%$ & 12.5 & $30 \%$ & $5 \mathrm{~min}$ \\
\hline B & $\begin{array}{l}\text { Urban } \\
\text { Metro }\end{array}$ & 2 & $5,950 \mathrm{~m}$ & $89 \%$ & 27.0 & $14 \%$ & $3 \mathrm{~min}$ \\
\hline C & $\begin{array}{l}\text { Regional } \\
\text { Line }\end{array}$ & 3 & $6,000 \mathrm{~m}$ & $83 \%$ & N/A & $30 \%$ & $15 \mathrm{~min}$ \\
\hline
\end{tabular}

Case A is a light rail suburban, single-track line, with several crossing stations to let it operate with a peak-hour headway of 5 minutes. Peak-hour volumes, at $30 \%$ of the daily ones, are quite high. Case B is a short double-track urban metro line, which is operated with a 3-minutes headway at peak-hours, and with a more balanced distribution of demand over the day (peak-hour volume is $14 \%$ of the daily one); as a result, this line carries more than the double of annual traffic compared to the previous one. Case $\mathrm{C}$ is a proposed new section for a regional line that, if realised, will operate with normal train-sets running at 15-minutes interval during peak-period. Located in a heavily urbanised area, this section should be built mostly underground.

Table 3: Example of results.

\begin{tabular}{|c|c|c|c|c|}
\hline & Case A & Case B & $\begin{array}{c}\text { Case C } \\
(2,000 \mathrm{p} / \mathrm{h})\end{array}$ & $\begin{array}{c}\text { Case C } \\
(6,000 \mathrm{p} / \mathrm{h})\end{array}$ \\
\hline Infrastructure Investment & $140 \mathrm{M} €$ & $423 \mathrm{M} €$ & \multicolumn{2}{|c|}{$504 \mathrm{M} €$} \\
\hline Rolling Stock Investment & $84 \mathrm{M} €$ & $225 \mathrm{M} €$ & \multicolumn{2}{|c|}{$150 \mathrm{M} €$} \\
\hline $\begin{array}{l}\text { Access Charges that would be needed to } \\
\text { balance the IM result }[€ / \text { train } \cdot \mathrm{km}]\end{array}$ & 5.11 & 19.72 & \multicolumn{2}{|c|}{26.45} \\
\hline Average Revenue per passenger & $1.18 €$ & $1.17 €$ & \multicolumn{2}{|c|}{$1.37 €$} \\
\hline Operational Deficit per passenger & $0.22 €$ & $-0.39 \epsilon$ & $2.82 €$ & $0.03 €$ \\
\hline Revenues as \% of OPEX & $84 \%$ & $149 \%$ & $33 \%$ & $98 \%$ \\
\hline Overall Deficit (IM+RU) per passenger & $0.84 €$ & $0.31 €$ & $9.06 €$ & $2.11 €$ \\
\hline Revenues as \% of Total Cost & $58 \%$ & $79 \%$ & $13 \%$ & $39 \%$ \\
\hline
\end{tabular}


Table 3 shows some of the results that a planner can get from the tool. Empirical evidence gathered for cases $\mathrm{A}$ and $\mathrm{B}$ confirm that the model behaviour is sound, as well as the magnitude of the results it produces. Case A, e.g., is representative of a well-managed and well-used suburban line, run with slight operational deficit (revenues are at about $84 \%$ of the "out-of-pocket" costs for running the line). If access charges had to be levied for using the infrastructure and cover its full cost (which is never the case for urban transport, and seldom for an interurban network), the fare should have been at $5.11 €$ per train kilometre; in this case, passenger revenues would cover $58 \%$ of the total cost, which - for a suburban service with high peak-hour rates - is still a fair performance. All those figures are comparable to the actual performance of the existing line on which this case was based.

Case B shows that its operation is even profitable, with the given fare structure. Total annual revenues exceed by $50 \%$ the annual operation expenses. The high cost of its infrastructure ( $89 \%$ of its length is built underground, and the rest is mainly bridges) combined to the high cost of signalling and train automation (to make it possible to run reliably with 3-minutes headway) makes that access charges are high, almost 4 times those of the Case A, in the very hypothetical case where the final user would have to cover the full cost of infrastructure. Despite this figure, and thanks to high and balanced demand levels, revenues are still $79 \%$ of the total annual expenses including capital ones for the infrastructure. The line could even be profitable, CAPEX and OPEX included, if a chunk of the investment for infrastructure was non-refundable.

The characteristics of Case $\mathrm{C}$ are a mix of the two previous cases. Demand is highly concentrated on peak-hour (with $30 \%$ of the daily volume), as in Case A. On the other hand, construction is extremely expensive, alike Case B, with most of the section built underground. This case is based on a proposal for a new section, for which the expected peak-hour demand is 2,000 passengers per direction. Conventional trains would operate, and the section could also be used as a by-pass of a main line section. Due to high construction costs and with a relatively low demand level, economic performance of the line qualifies as poor, at the best. Revenues cover only one third of the operational expenses, with an operational deficit of more than $2 \frac{1}{2}$ Euros per passenger. If the infrastructure costs were to be covered entirely, the average total cost per passenger (of more than 9 Euros) would be higher than a taxi ride for the same trip. Access charges to cover infrastructure costs would be extremely high, at 26.45 Euros per train · kilometre, more than 5 times those of the Case A.

Finally, the model has been used to estimate the demand level that is needed to balance the operational costs (and only those). The break-even point is at about 6,000 passengers per hour and direction; that is 3 times more than the most optimistic forecasts. On the other hand, as this section could be used by other trains, part of the access charges can be recovered from those, without asking for the services to bear the full burden of the capital expenses. Nevertheless, at only $33 \%$ of operational expenses covered by the expected revenues and a huge need for initial investment on infrastructure, chances for this project to be adopted are quite low. 


\section{Further developments}

What this paper is dealing with is part of an ongoing development. The aim is eventually to build a tool capable of computing the net present value for a project. This means that inflation rate should be accounted for. Along this line, evolution of the transport demand over time should also be reflected.

It should be noticed however that, even with mechanisms reflecting the demand growth and the inflation, the main target of the model will be kept: it is a tool to assess at a very early stage the relevance (economic and, indirectly, social) of a new rail line project. The tool is not meant to replace the more accurate evaluation process that should take place at every stage of a developing project. For this reason, a more detailed description of the demand (as O/D flows), or a non-linear depreciation policy are not considered as future developments.

\section{Conclusions}

The developed model currently fulfils the objectives it has been developed for. Planners facing proposals to invest in building new rail links can proceed with a very fast assessment, showing the economic viability of the idea. Computations are accurate enough to show if there is any interest to push the idea forward, or to drop it. Planners could use the tool to demonstrate to decision-makers the reasons making it worth or not to continue exploring the proposal that has been assessed. They are able to demonstrate its potential, if any, to assess the demand level that makes possible subsidies bearable or legitimate, or - in case of heavily unrealistic ideas - to "show the gap between the dream and the reality".

Utterly unrealistic ideas are not only funny. They may become noxious by polluting the debate on what it has to be done, and eventually become obstacles to necessary projects by delaying (and even locking, sometimes) the decisionmaking process.

Conversely, ideas that go against what one may call "common sense" sometimes prove eventually sound. In such cases, an initial fast positive assessment may be quite useful in avoiding them to be stopped dead in their track.

\section{References}

[1] Baumgartner, J.-P., Prices and costs in the railway sector, Institut des transports et de planification, École polytechnique fédérale de Lausanne, 2001; downloadable at:

http://litep.epfl.ch/files/content/sites/litep/files/shared/Liens/Downloads/Div ers/Baumgartner_Couts_chf_2001_e.pdf

[2] Gindrat, R., Pertinence de la construction d'une nouvelle ligne ferroviaire; Modèle économique, Transport Intermodality and Planning Group, École polytechnique fédérale de Lausanne, 2013 